\title{
Congenital Cytomegalovirus Infection
}

\author{
Monika L. Dietrich, MD, John S. Schieffelin, MD \\ Department of Pediatrics, Tulane University School of Medicine, New Orleans, LA
}

Background: Congenital cytomegalovirus (cCMV) is the leading cause of nongenetic congenital hearing loss in much of the world and a leading cause of neurodevelopmental disabilities. Infected babies can be born to women who are seropositive and seronegative prior to pregnancy, and the incidence is approximately $0.6 \%-0.7 \%$ in the United States. Symptoms vary from mild to severe, and hearing loss can be delayed in onset and progressive.

Methods: We reviewed the literature to summarize the epidemiology, clinical manifestations, diagnosis, treatment, and future directions of cCMV.

Results: The best way to diagnose the infection is with polymerase chain reaction of urine or saliva within 3 weeks after birth, followed by a repeat confirmatory test if positive. Moderately to severely symptomatic neonates should be treated for 6 months with valganciclovir, and some practitioners also choose to treat infants who have isolated hearing loss only. Treatment is not recommended for asymptomatic infants. All infected infants should be screened for hearing loss and neurodevelopmental sequelae. Universal and targeted screening may be cost effective. Currently, no vaccine is commercially available, although multiple candidates are under study.

Conclusion: Congenitally acquired cytomegalovirus is found in all communities around the world with a disease burden that is greater than many other well-known diseases. Advances are being made in prevention and treatment; however, improved awareness of the disease among clinicians and patients is needed.

Keywords: Congenital cytomegalovirus, cytomegalovirus, cytomegalovirus infections, hearing loss, valganciclovir

Address correspondence to Monika Dietrich, MD, Department of Pediatrics, Tulane University School of Medicine, 1430 Tulane Avenue, Box 8408, New Orleans, LA 70112. Tel: (517) 899-8926. Email: mdietri@tulane.edu

\section{INTRODUCTION}

Cytomegalovirus (CMV) is the largest of the Herpesviridae ${ }^{1}$ and is fairly ubiquitous in its distribution, infecting approximately half of the population in high-income countries by adulthood and nearly everyone by early childhood in low- and middle-income countries. ${ }^{2,3}$ When it encounters a robust immune system, the virus often infects without causing many symptoms; most individuals who have been infected are unaware. The virus makes the biggest impact when it encounters immature or compromised immune systems, as in developing fetuses or immunocompromised persons. $^{4}$

This review focuses on congenital infection with CMV (cCMV), a disease that causes more cases of permanent disability than better-known conditions such as Down syndrome and spina bifida and is the leading cause of nongenetic congenital hearing loss in high-income countries. ${ }^{5}$

\section{EPIDEMIOLOGY}

CMV has found its way to every part of world. While disproportionately prevalent in low- and middle-income countries and in crowded communities with few resources, CMV affects people from all backgrounds and geographic locations. ${ }^{6}$ In the United States, approximately 0.6\%-0.7\% of newborns are born congenitally infected with $\mathrm{CMV}^{7}$ This number is likely higher in low- and middle-income countries. 2,8 Of infected infants, approximately $10 \%$ are symptomatic at birth, and approximately half experience long-term sequelae. Among the infants with cCMV who are asymptomatic at birth, an estimated $10 \%-15 \%$ will develop long-term sequelae. ${ }^{2}$ The most common long-term sequela is hearing loss. ${ }^{2,5,9}$

An infant may be infected following primary infection (a pregnant woman seroconverts during pregnancy) or following nonprimary infection (the mother has a recurrence of an existing infection or reinfection during pregnancy). ${ }^{10,11}$ In the United States, approximately half of women $<45$ years of age are seronegative, while in low-income countries, almost all people are CMV seropositive by a very young age. ${ }^{7,8}$ The rate of transmission to neonates from a woman who has primary infection during pregnancy is approximately $30 \%$, while the transmission rate from women who have nonprimary infection has been estimated to be approximately $1 \%,{ }^{12}$ although the nonprimary infection estimate is limited by inconsistent studies and the likely variability of transmission risk among populations. ${ }^{11}$ While the transmission rate is much higher in women who have primary infection in pregnancy vs those with nonprimary infection, because 
the risk of seroconversion in pregnancy is only approximately $2 \%$, the majority of cCMV-infected infants worldwide, including in the United States, are born to mothers who have nonprimary infections during pregnancy. ${ }^{7}$ From one-half to three-quarters of all congenitally infected infants are born to nonprimarily infected mothers in low seroprevalence settings, while in high seroprevalence settings, maternal nonprimary infection accounts for almost all congenitally infected infants. $^{10,13}$ Thus, even though the risk of infection to the fetus is thought to be higher in cases of primary infection during pregnancy, communities with high seropositivity will tend to have high cCMV infection rates.

CMV is transmitted through secretions; high loads of virus are demonstrated in saliva, urine, cervicovaginal secretions, and semen. ${ }^{14}$ Children $<5$ years of age, especially children $<2$ years of age, appear to be a particularly important nidus of primary infection for women because of their frequent exposure to children's saliva and to urine from wet diapers. ${ }^{15-18}$ A study from Brazil published in 2018 by Barbosa et al suggested that exposure to young children in the household also increased the risk for nonprimary congenital infection. ${ }^{19}$ Younger age is associated with significantly higher viral loads in saliva and urine. Young children in daycare seem to be at particular risk for shedding the virus. ${ }^{13,20}$ Sexual transmission may also be a source of infection in women. ${ }^{21}$ Finally, evidence indicates that women and infants can pass the virus back and forth through breastfeeding. ${ }^{22}$

CMV disproportionately affects certain communities more than others. Studies have shown that CMV seroprevalence is positively associated with poverty and poor socioeconomic indicators. ${ }^{23}$ A large study examining cause of death for the years 1990-2006 showed that Native American and African American babies were 2.34 and 1.89 times more likely to die from cCMV, respectively, compared to white babies. ${ }^{5}$ The greatest cCMV mortality is seen in the southern United States. ${ }^{24}$ Fowler et al found that African American babies also are disproportionately infected, even after adjusting for maternal age and socioeconomic status. ${ }^{25}$ Risk factors for cCMV differ depending on the population characteristics of the community. A study in France found that the highest risk group for primary infection, which occurs more often in areas of low to intermediate seroprevalence, was parous women with comparatively higher incomes, while the risk for nonprimary infection was greatest in women with lower socioeconomic status and was not affected by parity. ${ }^{10}$

\section{Recurrence of Established Infection vs Reinfection}

Little is known about the mechanisms of transmission in nonprimary infection or whether it occurs principally by reinfection or recurrence of established infection. Finding an answer to this question is important for prevention. ${ }^{11}$ CMV is a genetically diverse organism, both between and within hosts; genetic diversity can be found in the same person (for example, urine vs saliva). ${ }^{26}$ This diversity may contribute to the pathologic potential of the virus, perhaps allowing it to evade established immune mechanisms. ${ }^{26}$ Several studies have demonstrated acquisition of antibodies to new polymorphisms on major CMV glycoproteins in women already seropositive, indicating reinfection with different strains. ${ }^{14,27-30}$ A study following approximately 200 healthy seropositive women for 2-3 years and periodically testing for viral shedding demonstrated that these women commonly became viruric (83\%) and viremic (52\%) intermittently. Some women had evidence of reinfection using strainspecific antibody testing, while others did not. ${ }^{29,30}$

Strain-specific seroconversion, however, likely underestimates reinfections, given the genomic diversity of the virus. Additionally, a 2018 study demonstrated multiple episodes of reinfection between breastfeeding infants and mothers without evidence of strain-specific seroconversion, introducing the question of whether an antigenically distinct strain is even necessary for reinfection. ${ }^{22}$ Reinfection clearly occurs, as well as reactivation, but an understanding of the frequency and determinants of maternal nonprimary infection is still lacking.

\section{CLINICAL MANIFESTATIONS}

In the literature, definitions of symptomatic vs asymptomatic cCMV differ. Rawlinson et al developed consensus recommendations in 2017 after a meeting of experts at the 5th International Congenital Cytomegalovirus Conference in $2015 .^{31}$ In general, moderately to severely symptomatic cCMV is defined as babies who are infected and who have multiple manifestations or have central nervous system (CNS) involvement; mildly symptomatic cCMV is defined as infants who have one or two isolated manifestations that are mild and transient; asymptomatic cCMV with isolated sensorineural hearing loss (SNHL) is defined as babies who have no apparent clinical symptoms other than hearing loss; and asymptomatic CCMV is defined as infants who have no apparent abnormalities at birth and have normal hearing. ${ }^{31}$ Approximately $10 \%-15 \%$ of babies with cCMV will be symptomatic at birth, and approximately half of those babies will have permanent sequelae. Of the remaining asymptomatically infected babies, approximately $10 \%-15 \%$ will have permanent sequelae. ${ }^{2}$

Symptoms associated with cCMV that can present at birth include thrombocytopenia, hepatosplenomegaly, intrauterine growth restriction, hepatitis, CNS and ocular disease, and SNHL. ${ }^{31}$ Dogma held that primary infection in pregnancy results in more severe neonatal disease ${ }^{6}$; however, some recent (2006-2013) evidence has introduced questions about this commonly accepted opinion. For example, some studies have shown that hearing loss may be similar in infants born to women who were seropositive or seronegative prior to pregnancy. ${ }^{32-34}$ In addition, severity of infection likely depends on timing during pregnancy. CMV transmission is more likely to occur in the third trimester compared to the first, but more severe sequelae are associated with infection earlier in the pregnancy. ${ }^{35,36}$

\section{Hearing Loss}

cCMV is the leading nongenetic cause of SNHL in industrialized nations and a leading cause (along with congenital rubella) in low- and middle-income countries. ${ }^{2,37}$ Hearing loss may be present at birth in isolation or may be accompanied by other symptoms of the disease. ${ }^{38}$ According to a 2014 systematic review by Goderis et al, 1 in 3 children with symptomatic cCMV and 1 in 10 children with asymptomatic cCMV will have hearing loss, and of hearing-impaired children, cCMV is the likely causative agent $10 \%-20 \%$ of the time. ${ }^{33}$ However, the articles included in the review varied 
widely in outcomes and were primarily from high-income countries.

Hearing loss can be bilateral or unilateral and is often progressive in nature; worsening of and fluctuations in hearing loss are common. ${ }^{33,39}$ Hearing loss may also be delayed in onset ${ }^{40}$; one study found that more than half of SNHL caused by $\mathrm{CCMV}$ would be missed with an initial newborn hearing screen. ${ }^{41}$ Progression and delayed onset of SNHL have been documented up to adolescence; however, the risk of new SNHL beyond 5 years of age appears to be minimal. ${ }^{39}$ Risk factors for developing hearing loss include CNS involvement at birth and high levels of CMV DNA in the blood at birth. ${ }^{42,43}$

\section{Neurodevelopmental Outcomes}

Neurodevelopmental long-term sequelae are a major concern with cCMV, particularly when the infant is symptomatic at birth. In a study of 160 symptomatic cCMV infants, CNS involvement was found in $52.5 \%$, including microcephaly, seizures, lethargy or hypotonia, poor suck, and neuroimaging findings. ${ }^{42}$ In the same study, $35 \%$ of 88 tested children had an intelligence quotient (IQ) $<70$. Another study following 76 symptomatic cCMV patients identified $43 \%$ with intellectual disability. ${ }^{44}$ A study in Sweden compared 26 children with CCMV identified as the cause for hearing loss with a control group of 13 children with hearing loss secondary to a common genetic mutation. ${ }^{45}$ The majority of the children in the cCMV group had balance disturbances (88\%), and 4 children had autism spectrum disorders, 2 had attention deficit hyperactivity disorder, and 2 had cerebral palsy compared to no occurrences of these conditions in the control group. This study is limited by its retrospective design and small sample size.

Babies with CNS abnormalities at birth, including microcephaly, are at increased risk for developing long-term neurodevelopmental sequelae. ${ }^{46}$ Different CNS abnormalities, from mild to severe, are seen in infants with cCMV. One study examined neurologic imaging of babies with CCMV and found germinolytic cysts, lenticulostriate vasculopathy, white matter signal intensity abnormalities, polymicrogyria, periventricular calcifications, white matter cysts, cerebellar hypoplasia, and ventriculomegaly. ${ }^{47}$ In this study, the most severe imaging findings were associated with primary infection in the first trimester. A 2017 European expert consensus statement drafted by the European Society for Paediatric Infectious Diseases recommended cranial ultrasound for all infants diagnosed with CCMV and follow-up magnetic resonance imaging (MRI) for any neonates with abnormality on cranial ultrasound. ${ }^{48}$ The statement acknowledges that a minority of experts would perform MRI on all cCMVdiagnosed infants, and a majority would perform MRI on infants who are symptomatic. The evidence, however, is limited, and at this time it is unclear if MRI provides any additional benefit to prognosis when used as a first-line imaging modality. However, MRI may demonstrate pathology that is not seen on cranial ultrasound. ${ }^{49,50}$

Also of interest are neurodevelopmental sequelae in babies who are asymptomatic at birth. These sequelae, which may be subtle and not discovered until later in life, combined with the lack of routine screening at birth, make robust studies of outcomes difficult to undertake., 9,51 However, some evidence is promising. Lopez et al followed 89 children who were asymptomatically infected at birth through 18 years of life, looking at IQ, vocabulary, and academic achievement in math and reading. ${ }^{52}$ They found no significant differences between the children who were congenitally CMV infected and had normal hearing and the control group. More studies with carefully matched cases and controls, rigorous neurodevelopmental testing, and diverse settings would be helpful to pick up subtle outcomes in this population. ${ }^{53}$

\section{Ocular Outcomes}

Children with cCMV may also have visual sequelae. These outcomes tend to be much less frequent in children with asymptomatic cCMV compared to infants symptomatic at birth. ${ }^{54}$ In one study, severe visual impairment was found in $18.2 \%$ of children with symptomatic cCMV. ${ }^{55}$ The study demonstrated that visual defects are not typically progressive or delayed in onset, unlike SNHL. The most common sequelae were strabismus, chorioretinal scars, cortical visual impairment, nystagmus, and optic nerve atrophy.

\section{DIAGNOSIS}

Postnatal diagnosis of cCMV is done preferably via realtime polymerase chain reaction (PCR) of saliva, urine, or both as soon as possible after birth and within 3 weeks after birth. Clinicians should note that testing saliva in the delivery room may increase the risk of false-positives from cervicovaginal secretions; also, saliva should be obtained at least 1 hour after breastfeeding. Any positive PCR should be confirmed with a repeat sample. ${ }^{10,31} \mathrm{PCR}$ is superior to viral culture for diagnosis, ${ }^{56,57}$ and urine is not superior to saliva. ${ }^{14,58}$ Diagnosis beyond 3 weeks is challenging given the inability to distinguish between congenital and postnatal acquisition. ${ }^{31}$ Postnatal shedding of virus in breast milk is common in seropositive mothers, and one study showed that approximately one-third of breastfeeding infants acquired the virus from their mothers with a mean incubation time of 42 days. ${ }^{59}$ The retrospective analysis of dried blood spots as a diagnostic method has been studied, but the sensitivity of this method is low. ${ }^{60,61}$ Thus, if cCMV is not diagnosed at or shortly after birth, retrospective diagnosis of cCMV is very difficult.

Prenatal diagnosis in suspected cases can be made with culture or PCR for CMV of the amniotic fluid from amniocentesis because the virus can be detected in the urine of infected fetuses that is excreted into the amniotic fluid. ${ }^{31}$ Liesnard et al followed 237 pregnant women with suspected or confirmed primary CMV and found an overall $80 \%$ sensitivity of prenatal PCR of amniotic fluid and $100 \%$ specificity. ${ }^{62}$ They recommended testing after 21 weeks of gestation and at least 7 weeks after confirmed seroconversion. Testing earlier in pregnancy may decrease sensitivity.

\section{TREATMENT}

In 2003, Kimberlin et al demonstrated improved hearing outcomes with intravenous ganciclovir administered for 6 weeks, although most patients demonstrated significant neutropenia. ${ }^{63}$ In 2009, Oliver et al showed improved neurodevelopmental outcomes with the same treatment. ${ }^{64}$ Similar efficacy was also demonstrated by the use of valganciclovir compared to ganciclovir, allowing for oral treatment with fewer adverse effects. ${ }^{65}$ In 2015, another study by Kimberlin et al demonstrated the benefit of treatment for 
Table. Recommendations for Monitoring and Follow-Up in Children Being Treated for Congenital Cytomegalovirus ${ }^{31,48}$

\begin{tabular}{|c|c|}
\hline Monitoring & Follow-Up \\
\hline $\begin{array}{l}\text { Absolute neutrophil counts weekly for first } 6 \text { weeks, at week } 8 \text {, } \\
\text { and then monthly for the duration of therapy }\end{array}$ & $\begin{array}{l}\text { 1. Ophthalmic examination early in the course of treatment, } \\
\text { with follow-up examinations as recommended by the } \\
\text { ophthalmologist }\end{array}$ \\
\hline \multirow[t]{2}{*}{ Transaminases monthly } & $\begin{array}{l}\text { 2. Audiologic testing at 6-month intervals for the first } 3 \text { years } \\
\text { of life and annually thereafter through adolescence }\end{array}$ \\
\hline & $\begin{array}{l}\text { 3. Developmental assessments beginning at the first year of } \\
\text { life on a case-by-case basis }\end{array}$ \\
\hline $\begin{array}{l}\text { Consider therapeutic drug monitoring if viral load increases } \\
>1.0 \log _{10} \text { during treatment, if toxicity is suspected, or if the } \\
\text { patient has an increased risk of toxicity (eg, prematurity, } \\
\text { abnormal renal function). }\end{array}$ & $\begin{array}{l}\text { 1. Hearing every 3-6 months in the first year, every } 6 \text { months } \\
\text { until } 3 \text { years of age, and every } 12 \text { months until } 6 \text { years of age } \\
\text { 2. Pediatric infectious disease annual visits until at least } 2 \text { years } \\
\text { of age }\end{array}$ \\
\hline \multirow[t]{2}{*}{$\begin{array}{l}\text { Not evidence-based, and not consensus: Consider viral load } \\
\text { every } 2-4 \text { weeks while on therapy. }\end{array}$} & $\begin{array}{l}\text { 3. Neurodevelopmental assessment at } 1 \text { year of age in a child } \\
\text { development service }\end{array}$ \\
\hline & $\begin{array}{l}\text { 4. Ophthalmic assessment directed by ophthalmologist but at } \\
\text { a minimum, a baseline review and annually up to } 5 \text { years of } \\
\text { age }\end{array}$ \\
\hline
\end{tabular}

6 months vs 6 weeks, specifically in total ear hearing and neurodevelopmental scores at 24 months. ${ }^{66}$ All of these studies only included infants with a gestational age of 32 weeks or more; data on preterm infants are lacking.

All studies were done in infants with symptomatic cCMV, including infants with isolated hearing loss. While infants with symptomatic disease clearly benefited from treatment, the studies were not sufficiently powered to assess the benefit specifically in infants with isolated hearing loss. Thus, the consensus recommendations published in 2017 stated that the evidence to treat infants with only hearing loss was not sufficient. ${ }^{31}$ A study published in 2018 by Pasternak et al showed benefit for this group of children, with many infants demonstrating improved hearing on treatment. ${ }^{67}$ This study did not have a control group, however, and while the results are promising, they must be interpreted with caution.

The following recommendations are drawn from the consensus recommendations published in 2017 and drafted by an informal International Congenital Cytomegalovirus Recommendations Group convened at the 5th International Congenital Cytomegalovirus Conference in 2015, the 2017 European expert consensus statement drafted by the European Society for Paediatric Infectious Diseases, and the American Academy of Pediatrics Red Book. ${ }^{31,48,68}$ The general agreement is to treat infants who are moderately to severely symptomatic at birth, and many experts also recommend treating infants with hearing loss only. Treatment consists of oral valganciclovir at a dose of 32 $\mathrm{mg} / \mathrm{kg} /$ day divided twice daily (16 mg/kg/dose) for a duration of 6 months. If oral treatment is not possible, ganciclovir may be given intravenously at a dose of $12 \mathrm{mg} / \mathrm{kg} /$ day divided twice daily. Adverse effects with valganciclovir are less common than with ganciclovir. Significant neutropenia occurs in approximately two-thirds of babies treated with ganciclovir and approximately one-fifth of babies treated with valganciclovir. ${ }^{63,66}$ Hepatotoxicity and thrombocytopenia may also be observed, especially with ganciclovir. ${ }^{69}$
Long-term side effects are not well studied in infants treated with ganciclovir or valganciclovir; a theoretical risk of gonadotoxicity and carcinogenicity has been suggested by animal studies only. ${ }^{48}$ Monitoring for adverse effects is warranted, with a proposed strategy suggested by the consensus statements outlined in the Table. ${ }^{31,48}$

As our understanding of CMV develops, novel therapeutics will be developed. One example is a drug the US Food and Drug Administration approved in 2017 for the prevention of CMV infection in patients undergoing stem cell transplant. Letermovir is unique in that the mechanism of action targets the CMV terminase complex instead of the viral DNA polymerase that current drugs target. ${ }^{70,71}$ While letermovir is not approved for use in cCMV and dosing is not available, novel ways to approach treatment for these infants are on the horizon.

\section{SCREENING}

The 2017 consensus recommendations developed following the 5th International Congenital Cytomegalovirus Conference in 2015 state that consideration should be given to universal neonatal CMV screening to enable early detection of $\mathrm{CCMV}^{31}$ Currently, no countries in the world have established universal cCMV screening, although legislative efforts in a number of states in the United States are growing, and select states (Connecticut, Utah, lowa) require screening for infants who fail their newborn hearing screen, known as targeted screening. ${ }^{40,72,73}$ While targeted screening will identify many infected infants, a number of infants will have delayed-onset hearing loss, and therefore their diagnoses will be missed. Universal screening would allow for careful monitoring of audiologic or neurodevelopmental sequelae that could then be treated with antivirals, developmental resources, or devices to aid hearing. ${ }^{40,41,74}$ A 2016 costeffectiveness analysis by Gantt et al concluded that both targeted and universal screening would result in net savings, assuming an improvement in hearing outcomes with antiviral therapy given to infants with clinical manifestations at birth, 
as well as benefits from earlier interventions in infants with hearing loss. ${ }^{75}$

\section{PREVENTION \\ Hyperimmune Globulin}

One major attempt at cCMV prevention has been the administration of hyperimmune globulin (HIG) to women primarily infected with the virus in pregnancy. Some animal and human studies have shown favorable outcomes in decreasing infection rates and severity of infection in cases of primary infection; however, a large 2014 randomized controlled trial, while showing trends of benefit, did not achieve statistical significance. ${ }^{31,76-78}$ Consequently, HIG is not currently the standard of care for primary or nonprimary CMV infection in pregnancy.

\section{Behavioral Changes}

Given the understanding that young children are the most common likely vector of infection in primary CMV, several groups have investigated how behavioral changes may impact the risk of infection with somewhat encouraging results. Revello et al instructed an intervention group of seronegative pregnant women in Italy to wash their hands frequently; avoid intimate contact such as kissing the child on the mouth or cheek; and avoid sharing of utensils, food, drinks, and washcloths. ${ }^{16}$ In the intervention group, $1.2 \%$ $(4 / 331)$ of the women seroconverted, while $7.6 \%(24 / 315)$ seroconverted in the control group. The study also included a questionnaire, and the survey results showed that women felt lack of time was a barrier to following the recommendations, but knowledge of risks was important to them; furthermore, $93 \%$ of responders felt the interventions were worth suggesting to all pregnant women. A large study in France looked at the rate of congenital infection in an obstetric practice before and after implementation of similar educational recommendations and found a smaller rate of seroconversion after exposure to the education at 12 weeks of gestation $(0.19 \%)$ compared to education before the 12 -week visit $(0.42 \%) .{ }^{17}$ This study, however, lacked a true control group, which made it difficult to control for confounders.

Among the public, knowledge about cCMV and behavioral preventive efforts is not high, and education is not commonly performed in obstetric clinics. ${ }^{7}$ Several surveys in the United States have shown low rates of awareness; ${ }^{79-81}$ Doutre et al found in 2016, for example, that approximately $9 \%$ of women and approximately $5 \%$ of men were aware of cCMV. ${ }^{82}$ A 2009 survey of 305 members of the American College of Obstetricians and Gynecologists revealed that fewer than $50 \%$ reported counseling about cCMV, and even fewer described discussing specific behavioral measures. ${ }^{83}$ Most women queried in one of the surveys published by Ross et al in 2008 responded that undertaking the recommended actions to help prevent transmission would be easy. ${ }^{80}$ As of November 2018, 9 states had mandated some form of education regarding $\mathrm{CCMV}$, with further legislation proposed. ${ }^{72}$

\section{Vaccine Development}

Given the ubiquity of CMV in the environment and its substantial burden of infection, a vaccine against the virus would be an optimal tool for preventing congenital infections. A campaign to find an effective vaccine has been in process since the 1970s; significant advances have been made but no vaccine is currently commercially available. ${ }^{84}$ The vaccine development process has been challenging given the significant genetic diversity of the virus and its ability to evade immune mechanisms. Both $\mathrm{T}$ cell and antibody responses appear to be necessary to prevent congenital infection..$^{85-87}$

Initial vaccine studies began with attenuated laboratory strains of the virus (AD169 and Towne strains), but these could not match the levels of naturally acquired immunity. ${ }^{84}$ Since that time, various vehicles have been explored for conferring immunity, including adjuvanted recombinant protein vaccines, vaccines using viral vectors or based on viruslike particles, or replication-impaired or replication-defective vaccines, and contemporary platforms such as dense body vaccines. The major targets have been viral glycoproteins, initially $\mathrm{gB}$, but then later $\mathrm{gH} / \mathrm{gL}$ followed by a glycoprotein complex of major interest, the pentameric complex gH/gL/UL128/130/131. 84,88,89 Additionally, a major structural protein, pp65, is also a target, with one study showing that women with primary infection who did not transmit the virus to their infants tended to have more robust $T$ cell responses to pp65. 87

At this time, the optimal vaccine targets are unclear. Some argue that women of childbearing age should be vaccinated, while others argue that vaccinating the primary vector-young children-would confer optimal benefit. ${ }^{88}$ In 2014, Lanzieri et al described a mathematical model of pathogen transmission that showed targeting young children and adolescents would have the greatest impact in terms of decreasing the rates of cCMV. ${ }^{90}$ As progress is made toward realistic CMV vaccine development, an optimal goal is to confer immunity to CMV seronegative women and to also boost the immunity in CMV seropositive women where the burden of the disease is greatest.

\section{CONCLUSION}

CCMV is found in all communities around the world and has a disease burden that is greater than many betterknown diseases. While the majority of infants are born without symptoms, some of those infants develop hearing loss, making CCMV the most common nongenetic cause of hearing loss in the United States and one of the most common causes in the world. Infants symptomatic at birth often develop long-term sequelae, including neurodevelopmental deficits. Advances are being made in prevention and treatment; however, improved awareness of the disease among clinicians and patients is needed.

\section{ACKNOWLEDGMENTS}

The authors have no financial or proprietary interest in the subject matter of this article.

\section{REFERENCES}

1. Sijmons S, Thys K, Mbong Ngwese M, et al. High-throughput analysis of human cytomegalovirus genome diversity highlights the widespread occurrence of gene-disrupting mutations and pervasive recombination. J Virol. 2015 May 13. pii: JVI.00578-15. doi: 10.1128/JVI.00578-15.

2. Manicklal S, Emery VC, Lazzarotto T, Boppana SB, Gupta RK. The "silent" global burden of congenital cytomegalovirus. Clin Microbiol Rev. 2013 Jan;26(1):86-102.

doi: 10.1128/CMR.00062-12. 
3. Buxmann $\mathrm{H}$, Hamprecht $\mathrm{K}$, Meyer-Wittkopf $\mathrm{M}$, Friese K. Primary human cytomegalovirus (HCMV) infection in pregnancy. Dtsch Arztebl Int. 2017 Jan 27;114(4):45-52. doi: 10.3238/arztebl.2017.0045.

4. Kalser J, Adler B, Mach M, Kropff B, Puchhammer-Stöckl E, Görzer I. Differences in growth properties among two human cytomegalovirus glycoprotein O genotypes. Front Microbiol. 2017 Aug 22;8:1609. doi: 10.3389/fmicb.2017.01609.

5. Bristow BN, O'Keefe KA, Shafir SC, Sorvillo FJ. Congenital cytomegalovirus mortality in the United States, 1990-2006. PLoS Negl Trop Dis. 2011 Apr 26;5(4):e1140. doi: 10.1371/journal.pntd.0001140.

6. Britt WJ. Maternal immunity and the natural history of congenital human cytomegalovirus infection. Viruses. 2018 Aug 3;10(8).pii: E405. doi: 10.3390/v10080405.

7. Cannon MJ. Congenital cytomegalovirus (CMV) epidemiology and awareness. J Clin Virol. 2009;46:S6-S10.

8. Lanzieri TM, Dollard SC, Bialek SR, Grosse SD. Systematic review of the birth prevalence of congenital cytomegalovirus infection in developing countries. Int J Infect Dis. 2014 May;22:44-48. doi: 10.1016/j.ijid.2013.12.010.

9. Dollard SC, Grosse SD, Ross DS. New estimates of the prevalence of neurological and sensory sequelae and mortality associated with congenital cytomegalovirus infection. Rev Med Virol. 2007 Sep-Oct;17(5):355-363. doi: 10.1002/rmv.544.

10. Leruez-Ville M, Magny JF, Couderc S, et al. Risk factors for congenital cytomegalovirus infection following primary and nonprimary maternal infection: a prospective neonatal screening study using polymerase chain reaction in saliva. Clin Infect Dis. 2017 Aug 1;65(3):398-404. doi: 10.1093/cid/cix337.

11. Britt WJ. Congenital human cytomegalovirus infection and the enigma of maternal immunity. J Virol. 2017 Jul 12;91(15). pii: e02392-16. doi: 10.1128/JVI.02392-16.

12. Kenneson A, Cannon MJ. Review and meta-analysis of the epidemiology of congenital cytomegalovirus (CMV) infection. Rev Med Virol. 2007 Jul-Aug;17(4):253-276. doi: 10.1002/rmv.535.

13. Wang C, Zhang X, Bialek S, Cannon MJ. Attribution of congenital cytomegalovirus infection to primary versus non-primary maternal infection. Clin Infect Dis. 2011 Jan 15;52(2):e11-e13. doi: 10.1093/cid/ciq085.

14. Cannon MJ, Hyde TB, Schmid DS. Review of cytomegalovirus shedding in bodily fluids and relevance to congenital cytomegalovirus infection. Rev Med Virol. 2011 Jul;21(4):240-255. doi: 10.1002/rmv.695.

15. Revello MG, Campanini G, Piralla A, et al. Molecular epidemiology of primary human cytomegalovirus infection in pregnant women and their families. J Med Virol. 2008 Aug;80(8):1415-1425. doi: 10.1002/jmv.21243.

16. Revello MG, Tibaldi C, Masuelli G, et al. Prevention of primary cytomegalovirus infection in pregnancy. EBioMedicine. 2015 Aug 6;2(9):1205-1210. doi: 10.1016/j.ebiom.2015.08.003.

17. Vauloup-Fellous C, Picone O, Cordier AG, et al. Does hygiene counseling have an impact on the rate of CMV primary infection during pregnancy? Results of a 3-year prospective study in a French hospital. J Clin Virol. 2009 Dec;46Suppl 4:S49-S53. doi: 10.1016/j.jcv.2009.09.003.

18. Adler SP, Finney JW, Manganello AM, Best AM. Prevention of child-to-mother transmission of cytomegalovirus among pregnant women. J Pediatr. 2004 Oct;145(4):485-491. doi: 10.1016/j.jpeds.2004.05.041.

19. Barbosa NG, Yamamoto AY, Duarte G, et al. Cytomegalovirus shedding in seropositive pregnant women from a high-seroprevalence population: the Brazilian cytomegalovirus hearing and maternal secondary infection study. Clin Infect Dis. 2018 Aug 16;67(5):743-750. doi: 10.1093/cid/ciy166.

20. Cannon MJ, Stowell JD, Clark R, et al. Repeated measures study of weekly and daily cytomegalovirus shedding patterns in saliva and urine of healthy cytomegalovirus-seropositive children. BMC Infect Dis. 2014 Nov 13;14:569. doi: 10.1186/s12879-014-0569-1.

21. Handsfield HH, Chandler SH, Caine VA, et al. Cytomegalovirus infection in sex partners: evidence for sexual transmission. J Infect Dis. 1985 Feb;151(2):344-348.

22. Boucoiran I, Mayer BT, Krantz EM, et al. Nonprimary maternal CMV infection following viral shedding in infants. Pediatr Infect Dis J. 2018 Jul;37(7):627-631. doi: $10.1097 /$ INF.0000000000001877.

23. Lantos PM, Permar SR, Hoffman K, Swamy GK. The excess burden of cytomegalovirus in African American communities: a geospatial analysis. Open Forum Infect Dis. $2015 \mathrm{Nov}$ 20;2(4):ofv180. doi: 10.1093/ofid/ofv180.

24. Hotez PJ. Neglected infections of poverty in the United States of America. PLoS Negl Trop Dis. 2008 June 25;2(6):e256. doi: 10.1371/journal.pntd.0000256.

25. Fowler KB, Ross SA, Shimamura M, et al. Racial and ethnic differences in the prevalence of congenital cytomegalovirus infection. J Pediatr. 2018 Sep;200:196-201.e1. doi: 10.1016/j.jpeds.2018.04.043.

26. Renzette N, Pokalyuk C, Gibson L, et al. Limits and patterns of cytomegalovirus genomic diversity in humans. Proc Natl Acad Sci. 2015 Jul 28;112(30):E4120-8. doi: 10.1073/pnas.1501880112.

27. Yamamoto AY, Mussi-Pinhata MM, Boppana SB, et al. Human cytomegalovirus reinfection is associated with intrauterine transmission in a highly cytomegalovirus-immune maternal population. Am J Obstet Gynecol. 2010 Mar;202(3):297.e1-297.e8. doi: 10.1016/j.ajog.2009.11.018.

28. Boppana SB, Rivera LB, Fowler KB, Mach M, Britt WJ. Intrauterine transmission of cytomegalovirus to infants of women with preconceptional immunity. N Engl J Med. 2001 May 3;344(18):1366-1371. doi: 10.1056/NEJM200105033441804.

29. Arora N, Novak Z, Fowler KB, Boppana SB, Ross SA. Cytomegalovirus viruria and DNAemia in healthy seropositive women. J Infect Dis. 2010 Dec 15;202(12):1800-1803. doi: $10.1086 / 657412$.

30. Ross SA, Arora N, Novak Z, Fowler KB, Britt WJ, Boppana SB. Cytomegalovirus reinfections in healthy seroimmune women. J Infect Dis. 2010 Feb 1;201(3):386-389. doi: 10.1086/649903.

31. Rawlinson WD, Boppana SB, Fowler KB, et al. Congenital cytomegalovirus infection in pregnancy and the neonate: consensus recommendations for prevention, diagnosis, and therapy. Lancet Infect Dis. 2017 Jun; 17(6):e177-e188. doi: 10.1016/S1473-3099(17)30143-3.

32. Vries JJ, Zwet EW, Dekker FW, Kroes A, Verkerk PH, Vossen AC. The apparent paradox of maternal seropositivity as a risk factor for congenital cytomegalovirus infection: a population-based prediction model. Rev Med Virol. 2013 Jul;23(4):241-249. doi: 10.1002/rmv.1744.

33. Goderis J, De Leenheer E, Smets K, Van Hoecke H, Keymeulen A, Dhooge I. Hearing loss and congenital CMV infection: a systematic review. Pediatr. 2014 Nov;134(5):972-982. doi: 10.1542/peds.2014-1173.

34. Mussi-Pinhata MM, Yamamoto AY, Brito RMM, et al. Birth prevalence and natural history of congenital cytomegalovirus infection in a highly seroimmune population. Clin Infect Dis. 2009 Aug 15;49(4):522-528. doi: 10.1086/600882. 
35. Pass RF, Fowler KB, Boppana SB, Britt WJ, Stagno S. Congenital cytomegalovirus infection following first trimester maternal infection: symptoms at birth and outcome. J Clin Virol. 2006 Feb;35(2):216-220. doi: 10.1016/j.jcv.2005.09.015.

36. Enders G, Daiminger A, Bäder U, Exler S, Enders M. Intrauterine transmission and clinical outcome of 248 pregnancies with primary cytomegalovirus infection in relation to gestational age. J Clin Virol. 2011 Nov;52(3):244-246. doi: 10.1016/j.jcv.2011.07.005.

37. Smith RJ, Bale JF Jr, White KR. Sensorineural hearing loss in children. Lancet. 2005;365(9462):879-890.

38. Boppana SB, Ross SA, Fowler KB. Congenital cytomegalovirus infection: clinical outcome. Clin Infect Dis. 2013 Dec;57Suppl 4:S178-S181. doi: 10.1093/cid/cit629.

39. Lanzieri TM, Chung W, Flores M, et al. Hearing loss in children with asymptomatic congenital cytomegalovirus infection. Pediatr. 2017 Mar;139(3). pii: e20162610. doi: 10.1542/peds.2016-2610.

40. Ross S, Long SS, Kimberlin DW. Closer to universal newborn screening for congenital cytomegalovirus infection but far away from antiviral therapy in all infected infants. $J$ Pediatr. 2018 Aug;199:7-9. doi: 10.1016/j.jpeds.2018.03.062.

41. Fowler KB, Dahle AJ, Boppana SB, Pass RF. Newborn hearing screening: will children with hearing loss caused by congenital cytomegalovirus infection be missed? J Pediatr. 1999 Jul;135(1):60-64.

42. Pinninti SG, Rodgers MD, Novak Z, et al. Clinical predictors of sensorineural hearing loss and cognitive outcome in infants with symptomatic congenital cytomegalovirus infection. Pediatr Infect Dis J. 2016 Aug;35(8):924-926. doi: 10.1097/INF.0000000000001194.

43. Forner G, Abate D, Mengoli C, Palù G, Gussetti N. High cytomegalovirus (CMV) DNAemia predicts CMV sequelae in asymptomatic congenitally infected newborns born to women with primary infection during pregnancy. J Infect Dis. $2015 \mathrm{Jul}$ 1;212(1):67-71. doi: 10.1093/infdis/jiu627.

44. Lanzieri TM, Leung J, Caviness AC, et al. Long-term outcomes of children with symptomatic congenital cytomegalovirus disease. J Perinat. 2017 Jul;37(7):875-880. doi: 10.1038/jp.2017.41.

45. Karltorp E, Löfkvist U, Lewensohn-Fuchs I, et al. Impaired balance and neurodevelopmental disabilities among children with congenital cytomegalovirus infection. Acta Paediatr. 2014 Nov;103(11):1165-1173. doi: 10.1111/apa.12745.

46. Noyola DE, Demmler GJ, Nelson CT, et al. Early predictors of neurodevelopmental outcome in symptomatic congenital cytomegalovirus infection. J Pediatr. 2001;138(3):325-331. doi: $10.1067 / \mathrm{mpd} .2001 .112061$.

47. Oosterom N, Nijman J, Gunkel J, et al. Neuro-imaging findings in infants with congenital cytomegalovirus infection: relation to trimester of infection. Neonatology. 2015;107(4):289-296. doi: 10.1159/000375439.

48. Luck SE, Wieringa JW, Blázquez-Gamero D, et al. Congenital cytomegalovirus: a European expert consensus statement on diagnosis and management. Pediatr Infect Dis J. 2017 Dec;36(12):1205-1213. doi: 10.1097/INF.0000000000001763.

49. Capretti MG, Lanari M, Tani G, et al. Role of cerebral ultrasound and magnetic resonance imaging in newborns with congenital cytomegalovirus infection. Brain Dev. 2014 Mar;36(3):203-211. doi: 10.1016/j.braindev.2013.04.001.

50. Giannattasio A, Bruzzese D, Di Costanzo P, et al. Neuroimaging profiles and neurodevelopmental outcome in infants with congenital cytomegalovirus infection. Pediatr Infect Dis J. 2018 Oct;37(10):1028-1033. doi: 10.1097/INF.0000000000001974.
51. Williamson WD, Percy AK, Yow MD, et al. Asymptomatic congenital cytomegalovirus infection: audiologic, neuroradiologic, and neurodevelopmental abnormalities during the first year. Am J Dis Child. 1990 Dec;144(12):1365-1368.

52. Lopez AS, Lanzieri TM, Claussen AH, et al. Intelligence and academic achievement with asymptomatic congenital cytomegalovirus infection. Pediatrics. 2017 Nov; 140(5). pii: e20171517. doi: 10.1542/peds.2017-1517.

53. Boppana SB, Fowler KB. Insight into long-term neurodevelopmental outcomes in asymptomatic congenital cmv infection. Pediatrics. 2017 Nov;140(5). pii: e20172526. doi: 10.1542/peds.2017-2526.

54. Coats DK, Demmler GJ, Paysse EA, Du LT, Libby C. Ophthalmologic findings in children with congenital cytomegalovirus infection. J AAPOS. 2000 Apr;4(2):110-116.

55. Jin HD, Demmler-Harrison GJ, Coats DK, et al. Long-term visual and ocular sequelae in patients with congenital cytomegalovirus infection. Pediatr Infect Dis J. 2017 Sep;36(9):877-882. doi: 10.1097/INF.0000000000001599.

56. Pinninti SG, Ross SA, Shimamura M, et al. Comparison of saliva $P C R$ assay versus rapid culture for detection of congenital cytomegalovirus infection. Pediatr Infect Dis J. 2015 May;34(5):536-537. doi: 10.1097/INF.0000000000000609.

57. Ross SA, Ahmed A, Palmer AL, et al. Detection of congenital cytomegalovirus infection by real-time polymerase chain reaction analysis of saliva or urine specimens. J Infect Dis. 2014 Nov 1;210(9):1415-1418. doi: 10.1093/infdis/jiu263.

58. Cardoso ES, Jesus BLS, Gomes LG, Sousa SM, Gadelha SR, Marin $\mathrm{LJ}$. The use of saliva as a practical and feasible alternative to urine in large-scale screening for congenital cytomegalovirus infection increases inclusion and detection rates. Rev Soc Bras Med Trop. 2015 Mar-Apr;48(2):206-207. doi: 10.1590/0037-8682-0200-2014.

59. Hamprecht K, Maschmann J, Vochem M, Dietz K, Speer CP, Jahn G. Epidemiology of transmission of cytomegalovirus from mother to preterm infant by breastfeeding. Lancet. $2001 \mathrm{Feb}$ 17;357(9255):513-518. doi: 10.1016/S0140-6736(00)04043-5.

60. Boppana SB, Ross SA, Novak Z, et al. Dried blood spot real-time polymerase chain reaction assays to screen newborns for congenital cytomegalovirus infection. JAMA. $2010 \mathrm{Apr}$ 14;303(14):1375-1382. doi: 10.1001/jama.2010.423.

61. Ross SA, Ahmed A, Palmer AL, et al; CMV and Hearing Multicenter Screening (CHIMES) Study Group. Newborn dried blood spot polymerase chain reaction to identify infants with congenital cytomegalovirus-associated sensorineural hearing loss. J Pediatr. 2017 May;184:57-61.e1. doi: 10.1016/j.jpeds.2017.01.047.

62. Liesnard C, Donner C, Brancart F, Gosselin F, Delforge ML, Rodesch F. Prenatal diagnosis of congenital cytomegalovirus infection: prospective study of 237 pregnancies at risk. Obstet Gynecol. 2000 June;95(6 Pt 1):881-888.

63. Kimberlin DW, Lin CY, Sánchez PJ, et al. Effect of ganciclovir therapy on hearing in symptomatic congenital cytomegalovirus disease involving the central nervous system: a randomized, controlled trial. J Pediatr. 2003 Jul;143(1):16-25.

64. Oliver SE, Cloud GA, Sánchez PJ, et al. Neurodevelopmental outcomes following ganciclovir therapy in symptomatic congenital cytomegalovirus infections involving the central nervous system. J Clin Virol. 2009 Dec;46Suppl 4:S22-S226. doi: 10.1016/j.jcv.2009.08.012.

65. Kimberlin DW, Acosta EP, Sánchez PJ, et al. Pharmacokinetic and pharmacodynamic assessment of oral valganciclovir in the treatment of symptomatic congenital cytomegalovirus 
disease. J Infect Dis. 2008 Mar 15;197(6):836-845. doi: 10.1086/528376.

66. Kimberlin DW, Jester PM, Sánchez PJ, et al. Valganciclovir for symptomatic congenital cytomegalovirus disease. N Engl J Med. 2015 Mar 5;372(10):933-943. doi: 10.1056/NEJMoa1404599.

67. Pasternak Y, Ziv L, Attias J, Amir J, Bilavsky E. Valganciclovir is beneficial in children with congenital cytomegalovirus and isolated hearing loss. J Pediatr. 2018 Aug;199:166-170. doi: 10.1016/j.jpeds.2018.02.028.

68. Kimberlin D, Brady M, Jackson MA, Long S, eds. AAP Red Book. 31 ed. Itasca, IL: American Academy of Pediatrics; 2018:310-317.

69. Gwee A, Curtis N, Connell TG, Garland S, Daley AJ. Ganciclovir for the treatment of congenital cytomegalovirus: what are the side effects? Pediatr Infect Dis J. 2014 Jan;33(1):115. doi: 10.1097/INF.0000000000000032.

70. Ligat G, Cazal R, Hantz S, Alain S. The human cytomegalovirus terminase complex as an antiviral target: a close-up view. FEMS Microbio Rev. 2018 Mar 1;42(2):137-145.

doi: 10.1093/femsre/fuy004.

71. Marty FM, Ljungman $P$, Chemaly RF, et al. Letermovir prophylaxis for cytomegalovirus in hematopoietic-cell transplantation. N Engl J Med. 2017 Dec 21;377(25):2433-2444. doi: 10.1056/NEJMoa1706640.

72. National CMV Foundation. CMV Legislation. www.nationalcmv.org/cmv-research/legislation.aspx. Published 2018. Updated January 25, 2018. Accessed November 20, 2018.

73. Hilditch C, Liersch B, Spurrier N, Callander EJ, Cooper C, Keir AK. Does screening for congenital cytomegalovirus at birth improve longer term hearing outcomes? Arch Dis Child. 2018 Oct;103(10):988-992.

doi: 10.1136/archdischild-2017-314404.

74. Cannon MJ, Griffiths PD, Aston V, Rawlinson WD. Universal newborn screening for congenital CMV infection: what is the evidence of potential benefit? Rev Med Virol. 2014 Sep;24(5):291-307. doi: 10.1002/rmv.1790.

75. Gantt S, Dionne F, Kozak FK, et al. Cost-effectiveness of universal and targeted newborn screening for congenital cytomegalovirus infection. JAMA Pediatr. $2016 \mathrm{Dec}$ 1;170(12):1173-1180. doi: 10.1001/jamapediatrics.2016.2016.

76. Nigro G. Hyperimmune globulin in pregnancy for the prevention of congenital cytomegalovirus disease. Expert Rev Anti Infect Ther. 2017 Nov;15(11):977-986. doi: 10.1080/14787210.2017.1398081.

77. Revello MG, Lazzarotto T, Guerra B, et al. A randomized trial of hyperimmune globulin to prevent congenital cytomegalovirus. N Engl J Med. 2014 Apr 3;370(14):1316-1326. doi: 10.1056/NEJMoa1310214.
78. Nigro G, Adler SP. Hyperimmunoglobulin for prevention of congenital cytomegalovirus disease. Clin Infect Dis. 2013 Dec;57Suppl 4:S193-S195. doi: 10.1093/cid/cit586.

79. Jeon J, Victor M, Adler SP, et al. Knowledge and awareness of congenital cytomegalovirus among women. Infect Dis Obstet Gynecol. 2006;2006:80383. doi: 10.1155/IDOG/2006/80383.

80. Ross DS, Victor M, Sumartojo E, Cannon MJ. Women's knowledge of congenital cytomegalovirus: results from the 2005 HealthStyles ${ }^{\mathrm{TM}}$ survey. J Womens Health (Larchmt). 2008 Jun;17(5):849-858. doi: 10.1089/jwh.2007.0523.

81. Cannon MJ, Westbrook K, Levis D, Schleiss MR, Thackeray R, Pass RF. Awareness of and behaviors related to child-to-mother transmission of cytomegalovirus. Prev Med. 2012 May;54(5):351-357. doi: 10.1016/j.ypmed.2012.03.009.

82. Doutre SM, Barrett TS, Greenlee J, White KR. Losing ground: awareness of congenital cytomegalovirus in the United States. J Early Hear Detect Interv. 2016;1(2):39-48. doi: 10.15142/T32G62.

83. Ross DS, Rasmussen SA, Cannon MJ, et al. Obstetrician/gynecologists' knowledge, attitudes, and practices regarding prevention of infections in pregnancy. $J$ Womens Health (Larchmt). 2009 Aug;18(8):1187-1193. doi: 10.1089/jwh.2008.1288.

84. Plotkin SA, Boppana SB. Vaccination against the human cytomegalovirus. Vaccine. 2018 Apr 2. pii: S0264-410X(18)30288-3. doi: 10.1016/j.vaccine.2018.02.089.

85. McCormick AL, Mocarski ES. The immunological underpinnings of vaccinations to prevent cytomegalovirus disease. Cell Mol Immunol. 2015 Mar;12(2):170-179. doi: 10.1038/cmi.2014.120.

86. Bialas KM, Tanaka T, Tran D, et al. Maternal CD4+ T cells protect against severe congenital cytomegalovirus disease in a novel nonhuman primate model of placental cytomegalovirus transmission. Proc Natl Acad Sci U S A. 2015 Nov 3;112(44):13645-51350. doi: 10.1073/pnas.1511526112.

87. Fornara C, Cassaniti I, Zavattoni M, et al. Human cytomegalovirus-specific memory CD4+ T-cell response and its correlation with virus transmission to the fetus in pregnant women with primary infection. Clin Infect Dis. 2017 Oct 30;65(10):1659-1665. doi: 10.1093/cid/cix622.

88. Schleiss MR, Permar SR, Plotkin SA. Progress toward development of a vaccine against congenital cytomegalovirus infection. Clin Vaccine Immunol. 2017 Dec 5;24(12). pii: e00268-17. doi: 10.1128/CVI.00268-17.

89. Anderholm K, Bierle C, Schleiss M. Cytomegalovirus vaccines: current status and future prospects. Drugs. 2016;76(17):1625-1645. doi: 10.1007/s40265-016-0653-5.

90. Lanzieri TM, Bialek SR, Ortega-Sanchez IR, Gambhir M. Modeling the potential impact of vaccination on the epidemiology of congenital cytomegalovirus infection. Vaccine. 2014 Jun 24;32(30):3780-3786. doi: 10.1016/j.vaccine.2014.05.014.

This article meets the Accreditation Council for Graduate Medical Education and the American Board of Medical Specialties Maintenance of Certification competencies for Patient Care and Medical Knowledge. 